\title{
Enhancement of ergocalciferol (vitamin D) content in mushrooms by UV irradiation
}

\author{
Seong-Jin Choi* \\ Department of Biotechnology, Daegu Catholic University, Daegu 38430, Korea
}

\section{자외선 조사에 의한 버섯의 ergocalciferol(비타민 D) 함량의 증진}

\author{
최성진* \\ 대구가톨릭대학교 생명공학과
}

\begin{abstract}
Ergocalciferol is known as having vitamin D activity. In this study, the effects of UV irradiation on the increase of egocalciferol content were investigated in 7 kinds of mushrooms, i.e, lily mushroom (Flammulina velutipes), oyster mushroom (Pleurotus ostreatus), young oyster mushroom (Pleurotus ostreatus), king oyster mushroom (Pleurotus eryngii), button mushroom (Agaricus bisporus), shiitake (Lentinula edodes), and wood ear mushroom (Auricularia auricula-judae). Mushrooms which were not exposed to UV light contained negligible amount of ergocalciferol in all kinds of tested mushrooms, but UV irradiation increased their content of ergocalciferol. Of UV A, B and C, UV B light was the most effective to increase ergocalciferol contents. In mushrooms, the increase in ergocalciferol content occurred only in the peel within $1 \mathrm{~mm}$ depth from the surface, which was directly exposed to the UV light. Therefore, when fresh whole mushrooms were iradiated with UV light, lily mushroom, the mushroom with a larger surface area compared to volume, such as lily mushroom, was more favorable in producing ergocalciferol. On the other hand when the mushrooms were freeze-dried and cut, the mushrooms with a higher ergosterol, such as king oyster mushroom, shiitake or button mushroom, were more favorable in generating ergocalciferol.
\end{abstract}

Key words : mushroom, UV irradiation, ergocalciferol, vitamin D, ergosterol

\section{서 론}

지용성인 비타민 $\mathrm{D}$ 를 함유하는 식품은 흔치 않으며 주로 연어, 고등어, 참치 등과 같이 지방 함유량이 높은 생선류에 소량 함유되어 있는 것으로 알려져 있다(1). 일반적으로 비타민은 인체에서 합성되지 않아 음식을 통해 섭취되어야 하는 필수 영양소를 일컫는다. 그러나 다른 종류의 비타민 과 달리 비타민 $\mathrm{D}$ 는 광화학적 반응에 의해 체내에서 생성되 며 이 때문에 때로는 비타민이 아닌 호르몬으로 간주되기도 한다(2). 체내에서 생성되는 비타민 $\mathrm{D}$ 는 비타민 $\mathrm{D}_{3}$ 로 일컬

*Corresponding author. E-mail : sjchoi@cu.ac.kr Phone : 82-53-850-3548, Fax : 82-53-850-3548

Received 17 May 2017; Revised 14 June 2017; Accepted 15 June 2017.

Copyright (c) The Korean Society of Food Preservation. All rights reserved.
어지는 cholecalciferol이다. 이 화합물은 피부가 일광에 노 출되면 cholesterol에서 유래하는 7-dehydrocholesterol이 일 광에 포함되어 있는 자외선에 의해 광분해되어 생성된다 (3)

한편, 비타민 $\mathrm{D}$ 에는 동물성 sterol인 cholesterol에서 유래 하는 비타민 $\mathrm{D}_{3}$ (cholecalciferol) 이외에 식물성 sterol인 ergosterol(ES)에서 유래하는 ergocalciferol(EC)이 있으며, 이를 비타민 $\mathrm{D}_{2}$ 라 한다(3). 비타민 $\mathrm{D}_{3}$ 와 유사하게, 비타민 $\mathrm{D}_{2}$ 는 $\mathrm{ES}$ 가 자외선에 의해 광분해되어 생성된다. 그러나 이 반응은 인체에서는 일어나지 않는데, 이는 ES가 효모, 곰팡이, 버섯 등의 일부 생물에 분포하고 인체에는 존재하 지 않기 때문이다. 그럼에도 불구하고 비타민 D2는 인체에 서 비타민 $\mathrm{D}$ 의 활성을 나타내는 것으로 보고되어 있다. 즉, 인체에서, 비타민 $\mathrm{D}_{2}$ 는 비타민 $\mathrm{D}_{3}$ 와 마찬가지로 간과 신장에서 각각 25-hydroxyvitamin $\mathrm{D}(25(\mathrm{OH}) \mathrm{D})$ 와 1,25-dihydroxyvitamin $\mathrm{D}(1,25(\mathrm{OH}) 2 \mathrm{D})$ 로 차례로 전환되는데, 비타민 
$\mathrm{D}_{2}$ 에서 유래하는 $1,25(\mathrm{OH}) 2 \mathrm{D}_{2}$ 는 비타민 $\mathrm{D}_{3}$ 에서 유래하는 $1,25(\mathrm{OH}) 2 \mathrm{D}_{3}$ 와 동일하게 활성형의 비타민 $\mathrm{D}$ 로서 혈액을 타고 체내를 순환하면서 혈중 칼슘과 인의 농도를 조절하고 뼈의 형성을 촉진하는 호르몬의 기능을 수행한다 $(1,4,5)$.

동물의 cholesterol에 대응하여 식물 또는 균류는 다양한 종류의 phytosterol을 함유한다. 버섯은 특히 생체중 100 $\mathrm{g}$ 당 수십 밀리그램에 달하는 비교적 높은 수준의 $\mathrm{ES}$ 를 함유하는 것으로 보고되어 있다(6). ES는 cholesterol의 소화 흡수를 억제하고(7) 혈중 LDL cholesterol을 감소(8)시키는 등의 생리적 기능이 알려져 있기도 하다. 그러나 $\mathrm{ES}$ 의 보다 중요한 기능적 가치는 비타민 $\mathrm{D}$ 즉 $\mathrm{EC}$ 로 쉽게 전환될 수 있다는 점에 있다. 이러한 관점에서 근래에 들어 자외선 조사를 통하여 버섯의 $\mathrm{EC}$ 함량을 증진하려는 연구가 활발 히 수행되고 있는데(9-11), 본 연구에서는 국내의 재배 버섯 을 대상으로 자외선 조사의 $\mathrm{EC}$ 함량 증진 효과와 $\mathrm{EC}$ 함량 증진에 적합한 버섯의 종류를 조사하였다.

\section{재료 및 방법}

\section{실험재료}

팽이(Flammulina velutipes), 느타리(Pleurotus ostreatus), 애느타리(Pleurotus ostreatus), 새송이(Pleurotus eryngii), 양 송이(Agaricus bisporus), 표고(Lentinula edodes), 목이 (Auricularia auricula-judae) 등 7종의 버섯을 12월부터 3월 까지의 기간 동안 재배 농장으로부터 구입하여 자외선 조사 및 $\mathrm{EC}$ 와 $\mathrm{ES}$ 의 분석에 이용하였다.

\section{자외선의 조사}

자외선의 종류별 조사 실험에서는, 자외선 $\mathrm{A}(315-400$ $\mathrm{nm}), \mathrm{B}(280-320 \mathrm{~nm})$ 또는 $\mathrm{C}(100-280 \mathrm{~nm})$ 를 방출하는 자외 선 램프 $(8 \mathrm{~W}$, 직경 $16 \mathrm{~mm}$, 길이 $286 \mathrm{~mm}$, Phillips Lighting, Eindhoven, Netherlands) 각 5 개를 $3 \mathrm{~cm}$ 간격으로 배열하고 동결 건조한 버섯 분말을 램프 아래 $3 \mathrm{~cm}$ 지점에 얇게 펼쳐 놓은 후 램프를 점등하여 자외선을 10 분간 조사하였다. 그 러나 그 밖의 모든 실험의 경우에는, $280-360 \mathrm{~nm}$ 파장의 자외선 $\mathrm{B}$ 를 방출하는 램프 $(15 \mathrm{~W}$, 직경 $25.5 \mathrm{~mm}$, 길이 436 $\mathrm{mm}, \mathrm{G15T8E}$, Sankyo Denki, Japan)를 장착한 자외선 조사 장치를 제작하여 실험에 이용하였다(Fig. 1). 이 장치에서, 자외선 램프는 버섯의 상하좌우 $7 \mathrm{~cm}$ 거리에 위치하도록 총 4 개를 장착하고 버섯의 전체 표면이 고르게 자외선에 노출될 수 있도록 조사 장치의 내부 벽면에는 반사경을 부착하였으며. 온도 상승 방지용 환기팬을 장착하였다. 버 섯은 절단하지 않거나 약 $5 \mathrm{~mm}$ 의 두께의 절편으로 세절한 상태, 또는 건조하지 않거나 동결 건조한 상태로 일정 시간 동안 자외선을 조사하였다. 자외선 조사 후, 버섯은 곧바로 동결 건조하거나 상온에서 일정 시간 저장한 후 동결 건조
하여 $\mathrm{EC}$ 및 $\mathrm{ES}$ 의 분석에 이용하였다.

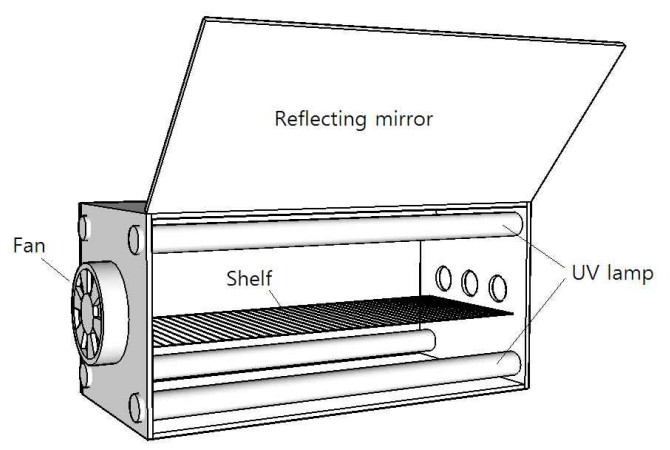

Fig. 1. UV illuminator used for UV treatment.

\section{$\mathrm{EC}$ 및 $\mathrm{ES}$ 의 추출}

예비실험을 통하여 최적의 $\mathrm{EC}$ 및 $\mathrm{ES}$ 의 추출 조건을 수립 하였으며 다음과 같은 방법으로 $\mathrm{ES}$ 및 $\mathrm{EC}$ 를 추출하였다. $4 \mathrm{~mL}$ 용량의 cap vial에 $100 \mathrm{mg}$ 의 동결건조 버섯시료를 넣고 $1 \mathrm{~mL}$ 의 $2 \mathrm{M} \mathrm{KOH} /$ ethanol 용액을 가하였다. 마개를 닫고 vortex 혼합한 후 heating block을 이용하여 $80^{\circ} \mathrm{C}$ 에서 10 분간 환류 가열하여 비누화 반응(saponification)을 유도 하였다. 반응물을 실온에서 식힌 후 $1 \mathrm{~mL}$ 의 $1 \mathrm{M} \mathrm{NaCl}$ 용액 과 $1 \mathrm{~mL}$ 의 hexane을 가하고 vortex 혼합하였다. 혼합물을 clinical centrifuge를 이용하여 $3,500 \mathrm{rpm}$ 에서 1 분간 원심분 리하여 hexane 층을 분리시킨 후 $0.75 \mathrm{~mL}$ 의 hexane 층을 $1.5 \mathrm{~mL}$ Ependorf tube에 회수하였다. 회수한 hexane 층에 $0.7 \mathrm{~mL}$ 의 $5 \% \mathrm{Na}_{2} \mathrm{CO}_{3}$ 용액을 가하고 vortex 혼합한 후, microcentrifuge를 이용하여 원심분리 $(14,000 \mathrm{rpm})$ 하여 hexane 층을 분리시켰다. 분리된 hexane 층 $0.5 \mathrm{~mL}$ 을 $2 \mathrm{~mL}$ sample vial에 회수한 후, 질소 가스를 불어넣어 용매를 제거 하였다. 건조한 잔사에 $0.5 \mathrm{~mL}$ 의 methanol을 가하고 vortex 혼합하여 용해한 후 이를 HPLC 분석용 시료로 이용하였다.

\section{$\mathrm{EC}$ 및 $\mathrm{ES}$ 의 분석}

$\mathrm{EC}$ 와 $\mathrm{ES}$ 는 Luna $\mathrm{C}_{18}$ 컬럼(particle size $3 \mu \mathrm{m}$, dimension $3.1 \times 150 \mathrm{~mm}$, Phenomenex, Torrance, CA, USA)을 장착한 HPLC(model 2695, Waters Co., Ltd., Miliford, MA, USA)를 이용하여 분석하였다. HPLC 분석에서, 시료 주입량은 1 $\mu \mathrm{L}$ 이었으며 용매는 methanol+acetonitrile(75:25, v/v)이었고 유속은 $0.35 \mathrm{~mL} / \mathrm{min}$ 이었다. $\mathrm{EC}$ 와 $\mathrm{ES}$ 의 동정에는 $\mathrm{PDA}$ 검출 기(model 2998, Waters Co., Ltd.)와 mass spectrometer(model 3100 , Waters Co., Ltd.)를 함께 이용하였으나, 일상적인 정 량은 PDA 검출기 $(265 \mathrm{~nm})$ 를 이용하였다. Mass spectrometer 의 경우, APCI+ 모드(corona current $15 \mu \mathrm{A}$, cone voltage $30 \mathrm{~V}$, desolvation 온도 $400^{\circ} \mathrm{C}$ )로 이온화하여 $\mathrm{m} / \mathrm{z} 300-500$ 의 범위에서 이온을 scanning하였다. 


\section{결과 및 고찰}

\section{$\mathrm{EC}$ 및 $\mathrm{ES}$ 의 분석}

$\mathrm{EC}$ 와 $\mathrm{ES}$ 는 분자식이 동일하게 $\mathrm{C}_{28} \mathrm{H}_{44} \mathrm{O}$ (mass=396)인데, $\mathrm{APCI}+$ 모드에서 이온화할 경우, $\mathrm{EC}$ 는 $\mathrm{m} / \mathrm{z}$ 397의 $[\mathrm{M}+\mathrm{H}]^{+}$를 우세하게 생성하는데 비해 ES는 m/z 379의 $\left[\mathrm{M}-\mathrm{H}_{2} \mathrm{O}+\mathrm{H}\right]^{+}$를 우세하게 생성하였다(Fig. 2). 이러한 특징은 시료의 chromatogram에서 peak를 확인하는데 활용되었다.
광분해됨으로써 생성되는데(3), 자외선 $\mathrm{B}$ 는 $\mathrm{ES}$ 의 광화학적 분해를 일으키기에 부족하거나(자외선 $\mathrm{A}$ ) 과하지(자외선 C) 않은 적합한 수준의 에너지를 지니는 것으로 생각된다.

자외선 $\mathrm{B}$ 의 조사 시간과 노출 정도에 따른 $\mathrm{EC}$ 생성의 차이

Fig. 4는 생 양송이 버섯에 자외선 $\mathrm{B}$ 를 시간별로 조사한 후 $\mathrm{EC}$ 와 $\mathrm{ES}$ 함량의 변화를 분석한 결과이다. 자외선에 노출 되지 않은 버섯에서는 $\mathrm{EC}$ 가 거의 검출되지 않았으나, 자외
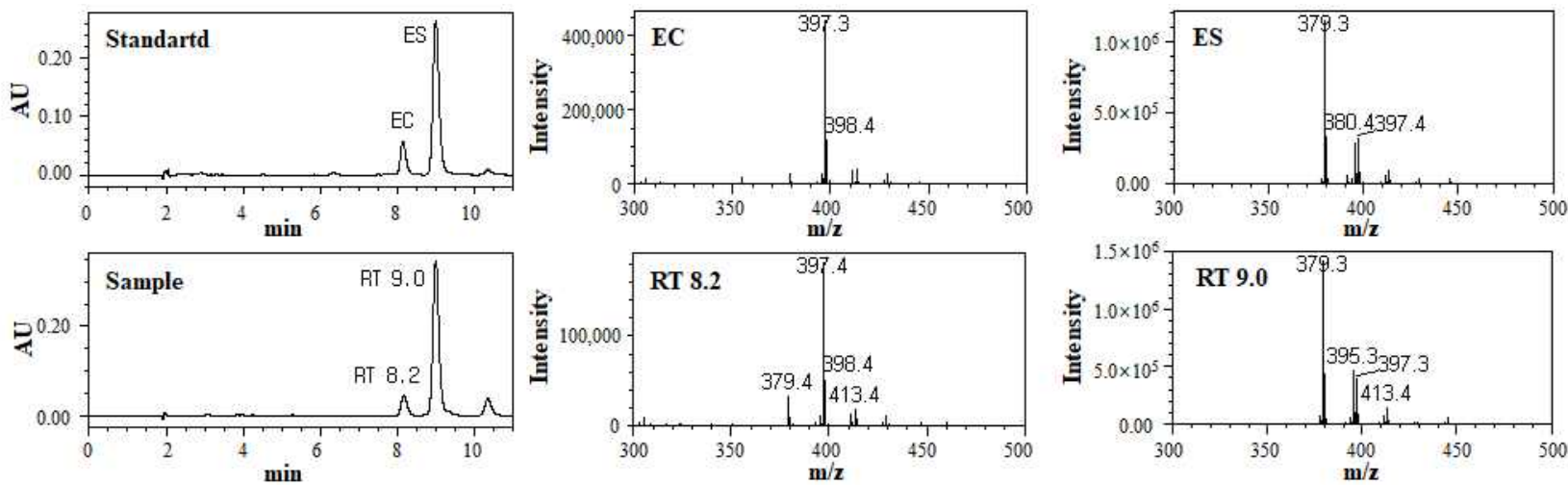

Fig. 2. HPLC chromatograms of ergosterol and ergocalciferol from authentic standard (left top) and presentative sample (left bottom) and their mass spectra (middle, ergocalciferol; right, er gosterol).

자외선의 종류별 $\mathrm{EC}$ 생성의 차이

Fig. 3은 동결 건조한 새송이 분말을 자외선 $\mathrm{A}, \mathrm{B}$ 또는 $\mathrm{C}$ 로 10 분간 조사한 후 $\mathrm{EC}$ 와 $\mathrm{ES}$ 함량의 변화를 조사한 결과 이다. 대조구의 경우 $\mathrm{EC}$ 함량은 검출 한계 농도 이하로 매우 낮았으며 자외선 $\mathrm{A}$ 의 조사에서는 $\mathrm{EC}$ 와 $\mathrm{ES}$ 의 함량이 대조구와 차이가 없었다. 그러나 자외선 $\mathrm{B}$ 또는 $\mathrm{C}$ 의 조사는 $\mathrm{EC}$ 의 생성을 유발하였으며 특히 자외선 $\mathrm{B}$ 는 $\mathrm{EC}$ 의 생성에 효과적이었다. 버섯에서 $\mathrm{EC}$ 는 $\mathrm{ES}$ 가 빛에너지를 흡수하여

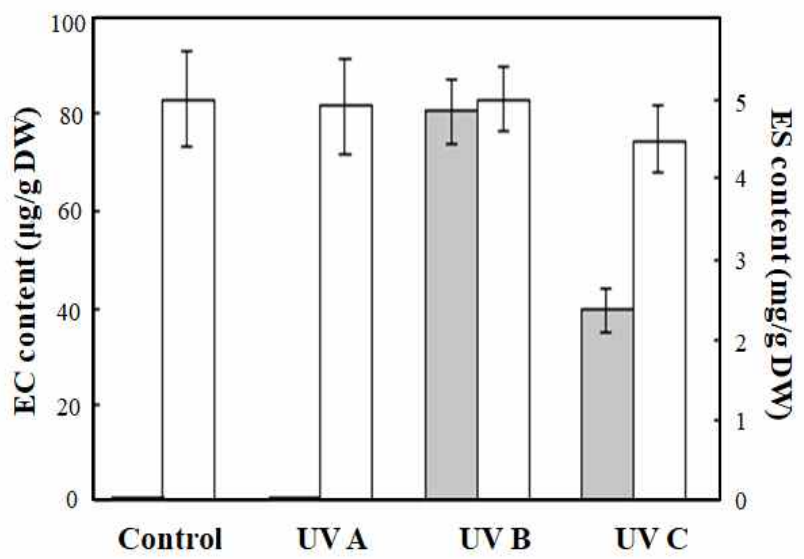

Fig. 3. Ergocalciferol $(\square)$ and ergosterol $(\square)$ contents in king oyster mushroom irradiated with UV A, B or C light for $10 \mathrm{~min}$. The powder of freeze-dried mushroom was treated with UV. Vertical bars show SD $(\mathrm{n}=3)$.
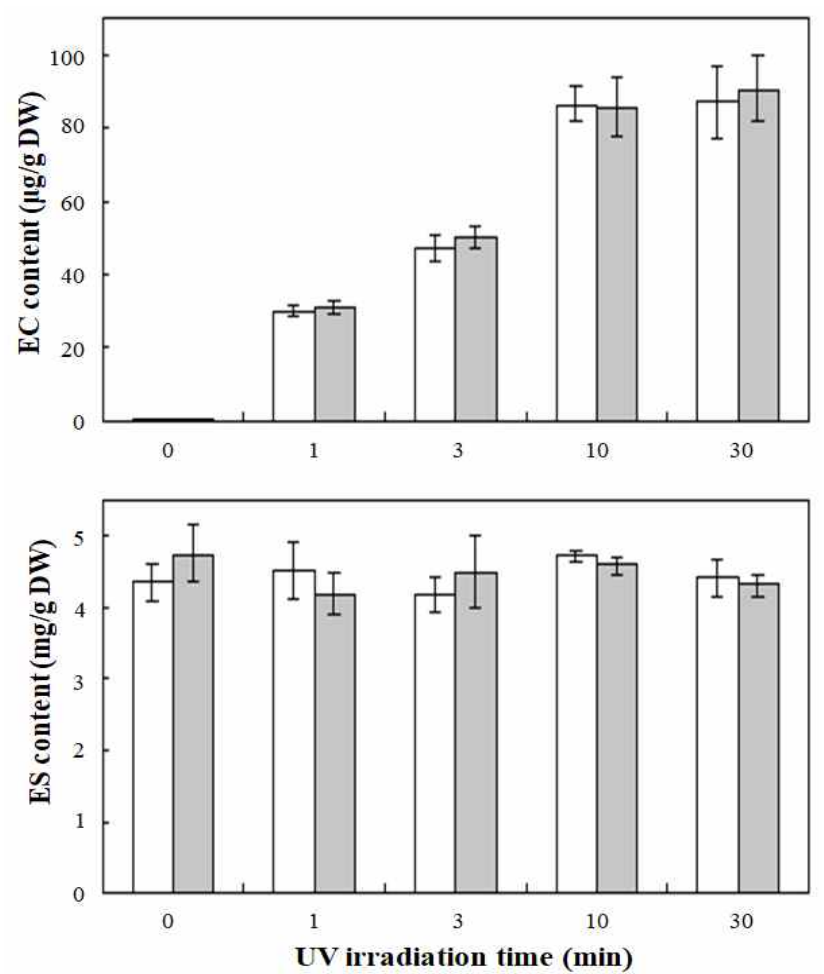

Fig. 4. Ergocalciferol (top) and ergosterol (bottom) contents in button mushrooms immediately $\square$ or 2 days $\square$ after irradiation with UV B light for varied times.

The fresh mushroom was treated with UV. Vertical bars show SD ( $n=3$ ). 
선을 조사한 경우 조사 시간의 증가와 더불어 $\mathrm{EC}$ 함량이 증가하였다. 그러나 10 분 이상 조사하더라도 $\mathrm{EC}$ 의 함량이 더 이상 증가하지는 않았다. 한편, 자외선을 조사한 버섯을 상온에 2 일 저장하더라도 $\mathrm{EC}$ 의 함량의 변화는 나타나지 않았다. 양송이 버섯에는 $4-5 \mathrm{mg} / \mathrm{g}$ of dry weight (DW) 수준 의 $\mathrm{ES}$ 가 함유되어 있는데 비해 자외선 조사에 의해 생성되 는 $\mathrm{EC}$ 는 $30-100 \mu \mathrm{g} / \mathrm{g} \mathrm{DW}$ 수준이었다. $\mathrm{EC}$ 의 생성량이 $\mathrm{ES}$ 함량에 비해 낮은 이유는 자외선의 침투성과 관련이 있는 것으로 보이므로, 이를 확인하기 위하여, 자외선 조사 후 버섯의 표피와 피층을 구분하여 $\mathrm{EC}$ 의 함량을 비교하였다 (Fig. 5). 자외선 조사에 의해 생성되는 $\mathrm{EC}$ 의 거의 대부분은 버섯 표면으로부터 $1 \mathrm{~mm}$ 깊이 이내의 표피에서만 생성되 었으며 자외선이 침투하지 못할 것으로 생각되는 $1 \mathrm{~mm}$ 깊이 이상의 피층에서는 $\mathrm{EC}$ 가 거의 생성되지 않았다. 이는 자외선 조사에 의해 일어나는 $\mathrm{EC}$ 의 생성이 수 분 이내의 짧은 시간 동안에 자외선에 직접적으로 노출되는 표면에 국한하여 진행되는 것임을 보인다.

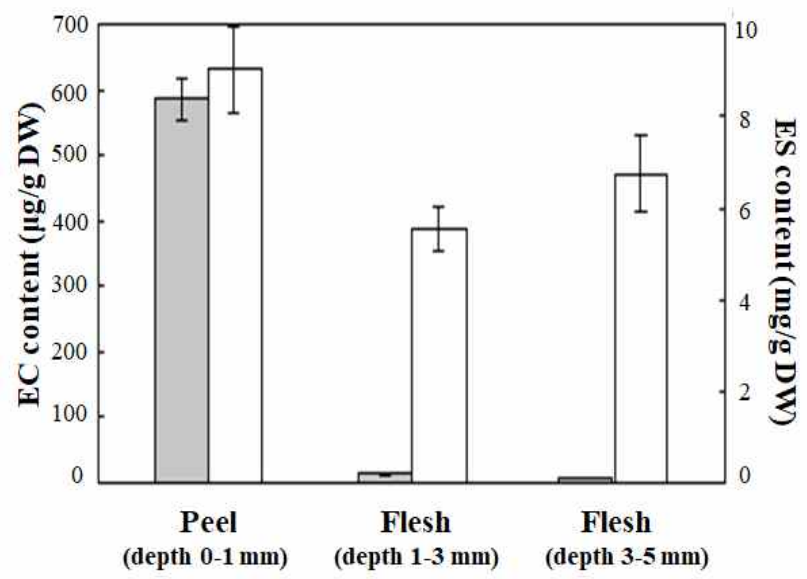

Fig. 5. Ergocalciferol $\square$ and ergosterol $(\square)$ contents in peel and flesh of button mushroom irradiated with UV B light for $10 \mathrm{~min}$. The fresh whole mushrooms were treated with UV, then peel and flesh from the cap of the mushrooms were separated for analysis. Vertical bars show SD $(n=3)$.

버섯의 종류 및 가공에 따른 $\mathrm{EC}$ 생성의 차이

Fig. 6은 팽이(lily mushroom), 느타리(oyster mushroom), 애느타리(young oyster mushroom), 새송이(king oyster mushroom), 양송이(button mushroom), 표고(Shiitake), 목이 (wood ear mushroom) 등 7종의 버섯을 온전한 생 버섯의 상태로 자외선 $\mathrm{B}$ 로 10 분간 조사한 후 $\mathrm{EC}$ 와 $\mathrm{ES}$ 의 함량 변화 를 조사한 결과이다. 단, 느타리와 새송이 버섯의 경우에는 갓과 줄기를 구분하여 조사하였다. 모든 종류의 버섯에서, 자외선을 조사하지 않았을 경우 $\mathrm{EC}$ 는 거의 검출되지 않았 으나 자외선 조사는 $\mathrm{EC}$ 의 함량을 증가시켰으며, 일단 증가 된 $\mathrm{EC}$ 함량은 실온에서 4일간 저장하는 동안에도 큰 변화 없이 유지되었다. 이 때, EC 함량의 증가는 버섯의 종류에 따라 차이가 있었는데, 특히 팽이와 느타리버섯(갓)에서
크게 증가한 반면 표고 또는 목이버섯의 경우는 증가가 크지 않았다. 한편, 버섯의 종류에 따라 $\mathrm{ES}$ 의 함량에도 차이 가 있었다. 즉, 새송이, 느타리, 양송이, 표고 등은 비교적 $\mathrm{ES}$ 함량이 높으나 팽이와 목이는 낮은 $\mathrm{ES}$ 함량을 보였다. 그러나 $\mathrm{EC}$ 의 함량과 $\mathrm{ES}$ 의 함량 간에는 유의적 상관관계가
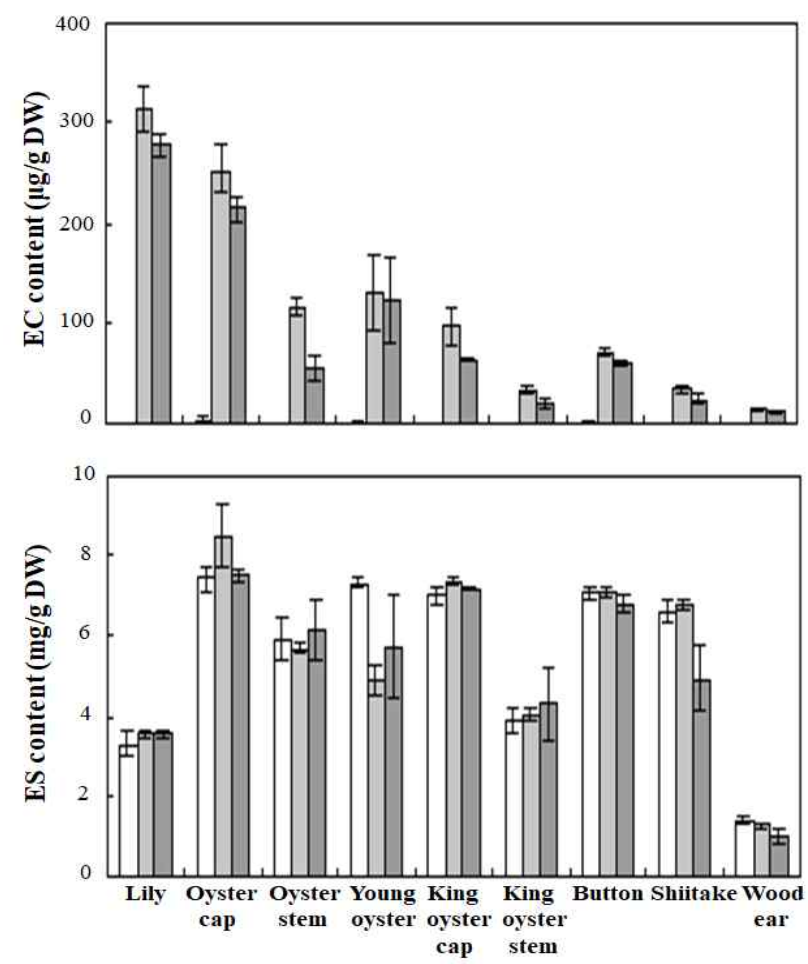

Fig. 6. Ergocalciferol (top) and ergosterol (bottom) content in various mushrooms immediately $(\square)$ and 4 days $(\square)$ after irradiation with UV B light for $10 \mathrm{~min}(\square$; Control).

The fresh whole mushrooms were treated with UV for $10 \mathrm{~min}$. Vertical bars show $\mathrm{SD}(\mathrm{n}=3)$.

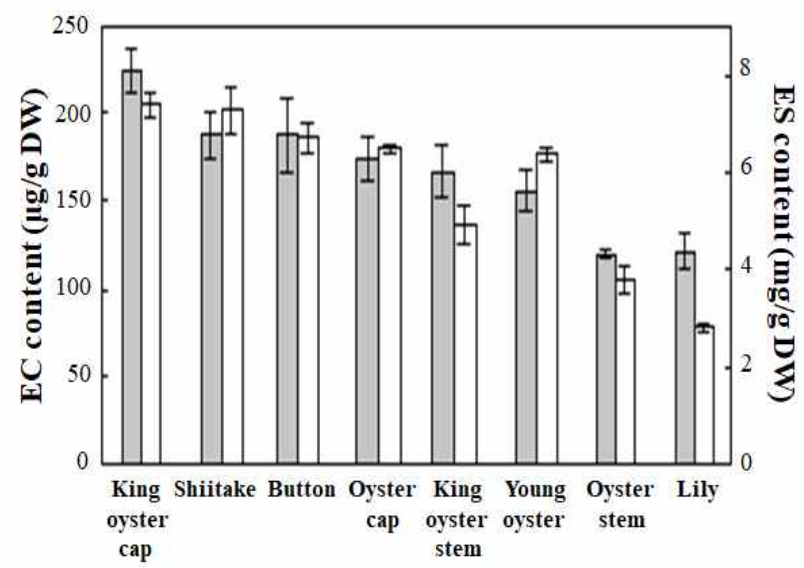

Fig. 7. Ergocalciferol $(\square)$ and ergosterol $(\square)$ content in various mushrooms irradiated with UV B light for $10 \mathrm{~min}$.

The slices of freeze-dried mushrooms were treated with UV. Vertical bars show SD $(n=3)$. 
발견되지 않았다(Fig. 9). 생 버섯을 온전한 상태로 자외선 을 처리하였을 때 버섯의 종류별 $\mathrm{EC}$ 생성의 차이는 아마도 버섯의 형태적 차이와 관련이 있는 것으로 생각된다. 즉, 자외선 조사에 따른 $\mathrm{EC}$ 의 생성이 표피에 국한된다는 앞의 실험 결과에 비추어 볼 때, 비록 $\mathrm{ES}$ 함량은 낮음에도 불구하 고 여러 버섯 중에서 체적에 비해 가장 넓은 표면적을 가지 는 팽이버섯에서, 그리고 느타리나 새송이의 경우에는 주 름이 있어서 줄기보다 표면적이 더 넓은 갓에서 $\mathrm{EC}$ 의 생성 이 더 많은 것으로 해석된다. 또한 버섯의 색 또한 $\mathrm{EC}$ 의 생성에 영향을 미치는 것처럼 보이는데, 표고나 목이버섯 은 표면이 갈색 또는 흑색이어서 자외선의 침투가 차단되어 $\mathrm{EC}$ 의 생성이 적은 것으로 생각된다.

온전한 생 버섯의 경우와 달리, 버섯을 세절하여 동결 건조한 후 자외선을 조사하였을 경우(Fig. 7), EC의 생성은

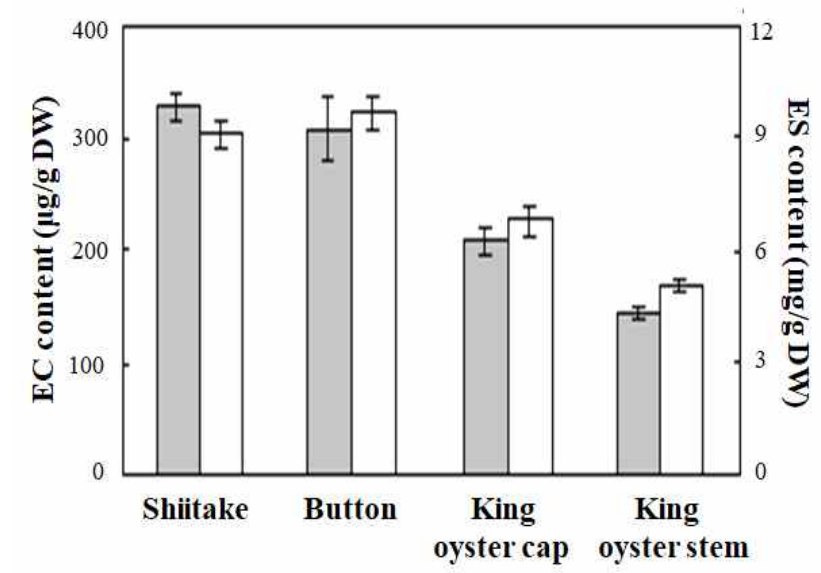

Fig. 8. Ergocalciferol $\square$ and ergosterol $\square$ content in varied mushrooms irradiated with UV B light for $10 \mathrm{~min}$.

The slices of fresh mushrooms were treated with UV. Vertical bars show SD (n=3).

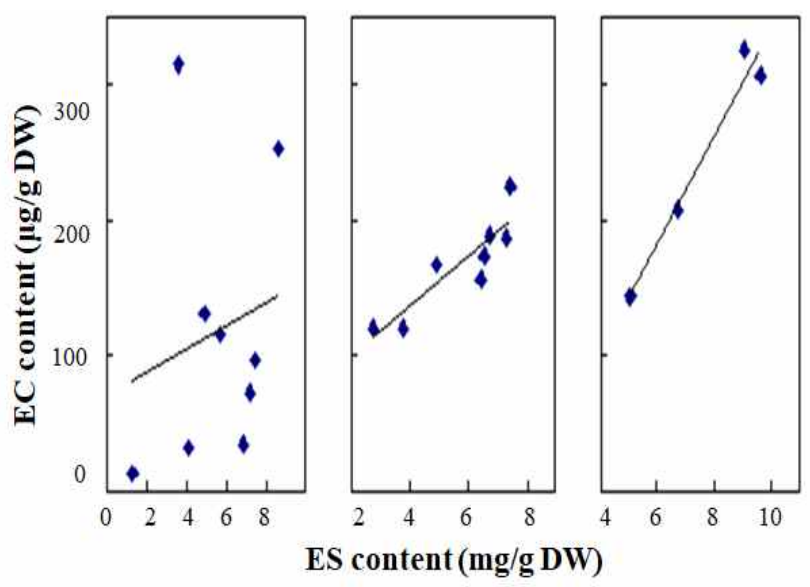

Fig. 9. Correlation between ergosterol content and ergocalciferol content in mushrooms, when they were treated with UV B light for $10 \mathrm{~min}$.

At the state of fresh wholes (left, $\mathrm{r}=0.190$; not significant), freeze-dried slices (middle, $\mathrm{r}=0.893 ; \mathrm{p}<0.05$ ), and fresh slices (right, $\mathrm{r}=0.979 ; \mathrm{p}<0.01$ ).
새송이 갓, 표고, 양송이 등에서 높게 나타난 반면 팽이버섯 은 가장 낮은 생성을 보였다. 또한, $\mathrm{EC}$ 의 함량과 $\mathrm{ES}$ 의 함량 사이에는 유의적 상관관계가 있는 것으로 나타났다(Fig. 9). 이는, 세절로 인해 자외선에 노출되는 표면적이 증가하 면 버섯의 형태적 특징은 더 이상 제한 요인이 되지 않으며, $\mathrm{EC}$ 의 직접적 생성 재료인 $\mathrm{ES}$ 함량이 $\mathrm{EC}$ 생성의 주요 변수 가 됨을 보인다. 이러한 결과는 비단 세절 후 건조한 버섯에 서 뿐만 아니라 생 버섯을 세절하여 자외선 조사하였을 때에도 동일하게 관찰되었다(Fig. 8). 단, 세절하여 자외선 을 조사한 경우, 생 버섯이 건조한 버섯에 비해 $\mathrm{EC}$ 의 함량이 약간 더 높은 경향을 보였다(Fig. 7,8).

\section{결 론}

흔히 버섯은 비타민 $\mathrm{D}$ 를 함유하는 식품으로 알려져 있으 나, 본 연구에서 다양한 종류의 재배 버섯을 분석한 결과 모든 버섯에서 $\mathrm{EC}$ 는 거의 함유되어 있지 않았다. 그러나 자외선 조사에 의해 $\mathrm{EC}$ 의 함량은 크게 증가하였다. 알려져 있는 바와 같이 $\mathrm{EC}$ 는 $\mathrm{ES}$ 의 자외선 조사에 따른 광분해 산물인데, 야생 버섯은 재배 버섯에 비해 $\mathrm{EC}$ 함량이 높으며 재배 버섯일지라도 재배 중 일광에 노출하거나 수확 후 일광 건조할 경우 $\mathrm{EC}$ 함량이 증가하는 것으로 보고되어있 기도 하다 $(12,13)$. 이는 일광에 포함되어있는 자외선의 작 용에 의한 결과이며 EC 생성에 유효한 자외선은 280-360 $\mathrm{nm}$ 파장의 자외선 $\mathrm{B}$ 인 것으로 조사되었다. 자외선은 식물 에서 stilbene(14) 또는 페놀화합물의 생성(15)을 증진하는 것으로 알려져 있기도 하다. 그러나 효소적 생합성 경로를 경유하는 이들 화합물과 달리 버섯의 $\mathrm{EC}$ 는 $\mathrm{ES}$ 의 steroid 고리구조 내 탄소 간 공유결합이 빛 에너지를 흡수하여 끊어짐으로써 생성된다(3). 그러므로 버섯에서 $\mathrm{EC}$ 의 생성 은 생 버섯 또는 건조 버섯의 구분이 없으며 단지 자외선에 직접적으로 노출되는 정도와 광분해의 기질인 $\mathrm{ES}$ 의 양에 따라 생성 정도가 결정될 뿐인데, 생 버섯 또는 건조 버섯에 서 세절 여부에 따라 $\mathrm{EC}$ 의 생성 정도에 차이가 있다는 사실 을 통하여 이를 확인할 수 있었다.

버섯의 $\mathrm{EC}$ 는 비타민 $\mathrm{D}_{3}$ 를 대신하여 비타민 $\mathrm{D}$ 섭취의 대안이 될 수 있다(1). 따라서 버섯의 비타민 D 함량을 증진 하기 위하여 자외선을 조사하고자 할 때, 생 버섯의 경우라 면 형태적으로 체적에 비해 표면적이 넓어서 자외선 노출에 유리한 버섯이 $\mathrm{EC}$ 의 생성에 유리하며 대표적으로 팽이 버 섯이 이에 속하는 것으로 조사되었다. 그러나 세절하여 건 조할 경우라면 광분해 기질인 $\mathrm{EC}$ 의 함량이 높은 버섯이 $\mathrm{EC}$ 의 생성에 유리하며 대표적으로 새송이, 표고 등이 이에 속하는 것으로 조사되었다.

\section{요 약}

Ergocalciferol은 vitamin $\mathrm{D}$ 의 활성을 가지는 것으로 알려 
져 있다. 본 연구에서는 팽이(Flammulina velutipes), 느타리 (Pleurotus ostreatus), 애느타리(Pleurotus ostreatus), 새송이 (Pleurotus eryngii), 양송이(Agaricus bisporus), 표고 (Lentinula edodes), 목이(Auricularia auricula-judae) 등 7종 의 버섯을 대상으로 자외선 조사에 따른 ergocalciferol(EC, 비타민 $\mathrm{D}_{2}$ ) 함량의 증진 효과를 조사하였다. 자외선을 조사 하지 않은 버섯의 ergocalciferol 함량은 극히 낮았으나 자외 선 조사에 의해 ergocalciferol 함량이 크게 증가하였으며, 자외선 $\mathrm{A}, \mathrm{B}, \mathrm{C}$ 중 특히 자외선 $\mathrm{B}$ 가 $\mathrm{EC}$ 함량 증진에 효과적 이었다. 버섯에서 ergocalciferol의 생성은 자외선에 직접 노출되는 부위 즉 깊이 $1 \mathrm{~mm}$ 이내의 버섯 표면에서만 일어 나는 것으로 조사되었다. 따라서 세절하지 않은 생 버섯에 자외선을 조사할 경우 팽이 버섯과 같이 체적에 비해 표면 적인 넓은 종류의 버섯에서 ergocalciferol 생성이 많았고, 건조 및 세절할 경우에는 EC 생성의 기질인 ergosterol의 함량이 높은 버섯에서 ergocalciferol 생성이 많았는데, 새송 이, 표고, 양송이 등이 이에 속하였다.

\section{감사의 글}

본 연구는 2017년도 대구가톨릭대학교 교내연구비 지원 으로 수행되었음.

\section{References}

1. Calvo MS, Whiting SJ, Barton CN (2005) Vitamin D intake: a global perspective of current status. J Nutr, 135, 310-316

2. Norman AW (2008) From vitamin D to hormone D: fundamentals of the vitamin D endocrine system essential for good health. Am J Clin Nutr, 88, 491-499

3. Zhu GD, Okamura WH (1995) Synthesis of vitamin D (calciferol). Chem Rev, 95, 1877-1952

4. Holick MF, Biancuzzo RM, Chen TC, Klein EK, Young A, Bibuld D, Reitz R, Salameh W, Ameri A, Tannenbaum $\mathrm{AD}$ (2008) Vitamin $\mathrm{D}_{2}$ is as effective as vitamin $\mathrm{D}_{3}$ in maintaining circulating concentrations of 25-hydroxyvitamin D. J Clin Endocrinol Metab, 93, 677-681

5. Keegan RJH, Lu Z, Bogusz JM, Williams JE, Holick MF (2013) Photobiology of vitamin D in mushrooms and its bioavailability in humans. Derm Endocrinol, 5, 165-176

6. Phillips KM, Ruggio DM, Horst RL, Minor B, Simon RR, Feeney MJ, Byrdwell WC, Haytowitz DB (2011) Vitamin D and sterol composition of 10 types of mushrooms from retail suppliers in the United States. J. Agric. Food Chem, 59, 7841-7853

7. de Jong A, Plat J, Mensink RP (2003) Metabolic effects of plant sterols and stanols. J Nutri Biochem, 14, 362-369

8. Lagarda MJ, Garcia LG, Farre R (2006) Analysis of phytosterols in foods. J Pharm Biomed Anal, 41, 1486-1496

9. Kalaras MD, Beelman RB, Holick MF, Elias RJ (2012) Generation of potentially bioactive ergosterol-derived products following pulsed ultraviolet light exposure of mushrooms (Agaricus bisporus). Food Chem, 135, 396-401

10. Guan W, Zhang J, Yan R, Shao S, Zhou T, Lei J, Wang Z (2016) Effects of UV-C treatment and cold storage on ergosterol and vitamin $\mathrm{D}_{2}$ contents in different parts of white and brown mushroom (Agaricus bisporus). Food Chem, 210, 129-134

11. Nolle N, Argyropoulos D, Ambacher S, Müller J, Biesalski HK (2016) Vitamin $D_{2}$ enrichment in mushrooms by natural or artificial UV-light during drying. LWT Food Sci and Technol, In Press

12. Mattila PH, Piironen VI, Uusi-Rauva EJ, Koivistoinen PE (1994) Vitamin D contents in edible mushrooms. J Agric Food Chem, 42, 2449-2453

13. Takamura K, Hoshino H (1995) Vitamin $D_{2}$ of shiitake mushrooms. New Food Ind, 37, 33-39

14. Wang W, Tang K, Yang HR, Wen PF, Zhang P, Wang HL, Huang WD (2010) Distribution of resveratrol and stilbene synthase in young grape plant (Vitis vinifera $\mathrm{L}$. cv. Cabernet Sauvignon) and the effect of UV-C on its accumulation. Plant Physiol Biochem, 48, 142-152

15. Luthria DL, Mukhopadhyay S, Krizek DK (2006) Content of total phenolics and phenolic acids in tomato (Lycopersicon esculentum Mill.) fruits as influenced by cultivar and solar UV radiation. J Food Composit Anal, 19, 771-777 